\title{
Alternative techniques of seeding cultured endothelial cells to ePTFE grafts of different diameters, porosities, and surfaces
}

\author{
Bengt Lindblad \\ Department of Surgery, University of Michigan Medical School, Ann Arbor, Michigan
}

\author{
Seth W. Wright, Ruth L. Sell and William E. Burkel \\ Department of Anatomy and Cell Biology, University of Michigan Medical School, \\ Ann Arbor, Michigan
}

Linda M. Graham and James C. Stanley

Department of Surgery, University of Michigan School of Medicine, Ann Arbor, Michigan

\begin{abstract}
Attachment of ${ }^{111}$ Indium-oxine labeled cultured canine venous endothelial cells to expanded polytetrafluorethylene (ePTFE) grafts was evaluated in vitro. Three alternative seeding techniques were studied in grafts having different diameters, porosities, and surfaces, including: (I) manual milking of blood containing endothelial cells within the graft; (II) a two-step procedure of incubating grafts initially with blood and then with an endothelial cell suspension; and (III) mechanical spinning of grafts filled with blood containing endothelium. Method II had significantly higher cell attachment to the graft $(11.6 \%)$ than did Method I $(1.5 \%)$ or III (4.7\%). A somewhat higher seeding efficiency was noted in $10-\mathrm{mm}-\mathrm{I}$. D. grafts $(11.6 \%)$ compared to
\end{abstract}

6-mm-I. D. grafts $(6.3 \%)$. Different graft porosity, created by altering internodal distances, did not cause significant changes in cell attachment $(10 \mu \mathrm{m}, 13.4 \% ; 30 \mu \mathrm{m}$, $6.3 \% ; 90 \mu \mathrm{m}, 16.0 \%$ ). Fibronectin-coated surfaces, which should have enhanced cell adhesion, demonstrated a $6.0 \%$ cell attachment, a lower efficiency than the $11.6 \%$ observed with a blood coating alone. Acetone-soaked surfaces, which should have predictably exhibited less hydrophobicity, produced quite variable attachments (range 3.4 to $59.7 \%$, mean $23.4 \%$ ). In the present investigation the best seeding technique was method II, the two-step incubation procedure. Consistant differences were not noted with various ePTFE graft configurations or surfaces.

\section{INTRODUCTION}

Prosthetic vascular grafts are frequently used in arterial reconstructive surgery. However, the inherent thrombogenicity of all currently used synthetic conduits limits their usefulness, particularly when placed in low-flow situations. Autologous endothelial cell seeding of both Dacron and ePTFE grafts in the canine model has been shown to result in the early formation of a nearly confluent luminal surface of endothelium. Such a surface should reduce graft thrombogenicity and increase patency.

Two factors may be important in assuring the clinical success of autologous endothelial cell seeding of vascular prostheses. The first relates to harvesting

Journal of Biomedical Materials Research, Vol. 21, 1013-1022 (1987)

(C) 1987 John Wiley \& Sons, Inc.

CCC 0021-9304/87/081013-10\$04.00 
endothelial cells in a manner that will minimize the amount of donor vein required. The second relates to increasing seeding efficiency by enhancing endothelial cell attachment to vascular grafts. The current study was conducted to compare the efficiency of indium-111-oxine ( ${ }^{111} \mathrm{In}$ )-labeled endothelial cell seeding onto ePTFE grafts using different seeding techniques in grafts with varying diameters, porosities, and surfaces.

\section{MATERIALS AND METHODS}

\section{Endothelial cell derivation and culture}

Endothelial cells from canine jugular veins were enzymatically harvested using a method previously reported from this laboratory. ${ }^{1}$ Ten- to twelve-cm segments of external jugular veins were excised, everted over 5-mm-diameter stainless-steel rods, and suspended in iced calcium and magnesium free Hanks' balanced salt solution, BSS-CMF (Gibco, Grand Island, NY). The veins were spun at $200-300 \mathrm{rpm}$ in fresh Hanks' BSS-CMF to remove adherent red blood cells. They were then immersed in $0.1 \%$ trypsin (Difco, Detroit, MI) in BSS-CMF with $0.125 \%$ ethylenediamine tetra-acetic acid (EDTA) at $\mathrm{pH}$ 8.0 for $10 \mathrm{~min}$ at $37^{\circ} \mathrm{C}$. This was followed by incubation in $0.5 \%$ collagenase, $630 \mathrm{U} / \mathrm{mL}$, (Worthington, Freehold, NJ; CLS type I) in Hanks' BBS with calcium and magnesium at $\mathrm{pH} 7.3$, for an additional 10 minutes at $37^{\circ} \mathrm{C}$. The veins were then spun in chilled Medium 199 (Gibco, Grand Island, NY). The pellet of cells derived by this means was washed once more in chilled Medium 199, spun, pelleted, and resuspended in $5 \mathrm{~mL}$ of tissue culture media. The endothelial cells were then placed in tissue culture flasks having $25 \mathrm{~cm}^{2}$ growth surface containing Medium 199 with $20 \%$ fetal bovine serum (Flow Laboratories, Rockville, MD); endothelial cell growth factor, $25 \mu \mathrm{g} / \mathrm{mL}$ (Seragen, Boston, MA); porcine intestinal heparin, $15 \mu \mathrm{g} / \mathrm{mL}$ (Sigma, St. Louis, MO) and gentamicin, $5 \mathrm{mg} / \mathrm{mL}$ (Schering, Kenilworth, NJ). The nutrient medium was changed every 2 to 3 days. Cells were subcultured when a confluent monolayer was formed.

\section{${ }^{111}$ Indium-oxine labeling}

Cells for nuclide labeling were removed from flasks with a $0.05 \%$ trypsinEDTA solution (Gibco, Grand Island, NY). The cells were washed, spun, and resuspended in Medium 199. Cells from several flasks were pooled. Cell numbers in reference samples were quantified using an automated counter (Coulter Electronics, Hialeah, FL). Tissue culture medium was added as needed to the cell pool to yield an eventual concentration of $10^{6}$ cells $/ \mathrm{mL}$. ${ }^{111}$ In-labeling was performed with a modification of the technique of Sharefkin and his colleagues. ${ }^{211}$ In-oxine (Mediphysics, Emeryville, CA) was diluted to an activity of approximately $100 \mu \mathrm{Ci} / \mathrm{mL}$ in Hank's BSS-CMF. Approximately $50 \mu \mathrm{Ci}$ of ${ }^{111}$ In-oxine was added per $10^{6}$ cells and allowed to incubate for $15 \mathrm{~min}$ at room temperature. The efficiency of radiolabeling 
by this methodology in our laboratory has ranged from 65-95\%, averaging $90 \%$. Following centrifugation the supernatant was discarded. The pellet was resuspended and washed twice in Hank's BSS-CMF. Labeled cells were then resuspended in Hank's BSS-CMF at a concentration of $10^{6}$ cells $/ \mathrm{mL}$ for use in graft seeding. Viability of cells derived and labeled by this means ranged from $80-90 \%$.

Four different variables affecting the seeding efficiency of ePTFE grafts were evaluated: (1) seeding technique, (2) graft diameter, (3) graft porosity, and (4) surface coating. Six grafts were evaluated in each experimental category. All conduits were $26 \mathrm{~cm}$ in length and approximately $10^{6}$ endothelial cells were seeded in each graft. The specific seeding technique or graft type were selected for study in a random manner.

\section{Seeding technique}

Standard 10-mm-I.D. ePTFE grafts with a $30-\mu \mathrm{m}$ internodal distances were used for this part of the study (Gore-tex grafts, W. L. Gore, Inc., Flagstaff, AZ).

\section{Method I}

Five $\mathrm{mL}$ of blood was mixed with $1 \mathrm{~mL}$ of the labeled endothelial cell suspension and manually milked along the luminal surface of the graft ten times.

\section{Method II}

Five $\mathrm{mL}$ of blood was placed in the graft for $5 \mathrm{~min}$ and then drained. One milliliter of the labeled endothelial cell suspension was mixed with $2 \mathrm{~mL}$ of Medium 199 containing endothelial cell growth factor, $25 \mu \mathrm{g} / \mathrm{mL}$. This mixture was then placed in the graft for $10 \mathrm{~min}$, and the conduit turned $90-180^{\circ}$ every minute during incubation.

\section{Method III}

The graft was placed on a 5-mm-diameter stainless-steel rod and a mixture of $5 \mathrm{~mL}$ blood and $1 \mathrm{~mL}$ endothelial cell suspension was placed in the graft. The ends of the graft were sealed with rubber corks, and the rod with the affixed graft was spun at approximately $1000 \mathrm{rpm}$ for $2 \mathrm{~min}$. The graft was then removed from the rod and drained of blood. Regardless of the seeding method used, all grafts were flushed in a standard fashion five times with $10 \mathrm{~mL}$ of blood containing $1000 \mathrm{IU}$ of heparin sodium at the completion of the seeding procedure. 
Graft size

Both $10-\mathrm{mm}$ and $6-\mathrm{mm}-\mathrm{I}$. D. ePTFE grafts were studied.

\section{Graft porosity}

ePTFE grafts (6 mm I. D.) with 10, 30, and $90 \mu \mathrm{m}$ internodal distances were evaluated. All grafts with different configurations were seeded using Method II.

\section{Graft surface coating}

Standard 10-mm-I. D. ePTFE grafts were used in this part of the study. Blood-coated surfaces were investigated using seeding Methods I and II as previously described.

\section{Fibronectin-coated surface}

Grafts were filled with fibronectin (Sigma, St. Louis, MO) dissolved in a Tris buffer solution $(10 \mu \mathrm{g} / \mathrm{mL})$. The fibronectin solution was allowed to incubate for $1 \mathrm{hr}$ in the graft. After evacuation of this solution, $1 \mathrm{~mL}$ of the endothelial cell suspension was mixed with $2 \mathrm{~mL}$ of Medium 199 containing $25 \mu \mathrm{g} / \mathrm{mL}$ of endothelial cell growth factor. This mixture was incubated within the graft for $10 \mathrm{~min}$ prior to flushing with heparinized blood. The graft was turned $90-180^{\circ}$ four times during the fibronectin incubation and every minute during the endothelial seeding. This has proven a reliable method in our and others' laboratories for coating ePTFE surfaces with fibronectin. ${ }^{3,4}$

\section{Acetone-soaked surface}

Grafts were soaked with acetone for $5 \mathrm{~min}$ in a standard manner to decrease their hydrophobic character. They were then rinsed vigorously with saline. Five milliliters of blood mixed with $1 \mathrm{~mL}$ of the endothelial cell suspension was milked through the conduits a total of ten times, before flushing with heparinized blood as described previously.

\section{Measurement of gamma activity}

Two 200- $\mu \mathrm{L}$ reference samples of the final solution of endothelial cells and blood or Medium 199 were removed for gamma counting prior to graft seeding. After completing the seeding procedure, all grafts were cut into $1-\mathrm{cm}$ segments and placed in counting vials. Gamma activity in the reference 
samples and the graft sections were immediately measured in a Packard Auto Gamma Scintillation Spectrometer. The percentage of cell seeding was calculated by determining the fraction of activity in cells seeded into the graft according to the formula:

$$
\text { Seeding efficiency }(\%)=\frac{\text { Total counts attached to the graft }}{\text { Total counts of cells used to seed the graft }} \times 100
$$

\section{RESULTS}

Large variations in seeding efficiency, ranging from 0.3 to $59.7 \%$, were seen among the different methods tested (Table I). Substantial differences were also found within each group investigated. Counts from the 26 sections of each graft demonstrated a somewhat irregular pattern of radioactivity (Fig. 1).

\section{Seeding techniques}

Method II was superior to other seeding techniques with a mean cell attachment of $11.6 \%$. The manual milking method (I) showed not only poor total seeding efficiency $(1.5 \%)$, but also lower cell attachment in graft midportions compared to the other two techniques $(p<0.01)$.

\section{Graft sizes}

Of the two diameters investigated, the 6-mm-I. D. graft had a seeding efficiency of $6.3 \%$, as compared to $11.6 \%$ for $10-\mathrm{mm}-\mathrm{I}$. D. grafts, a difference which was not statistically significant $(p>.1)$.

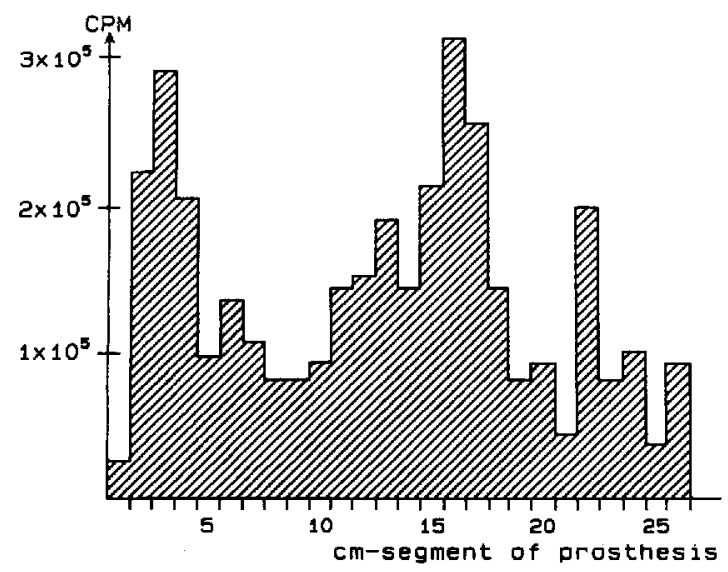

Figure 1. Variability in counts among 26 sequential $1.0 \mathrm{~cm}$ sections of grafts using seeding method II. 


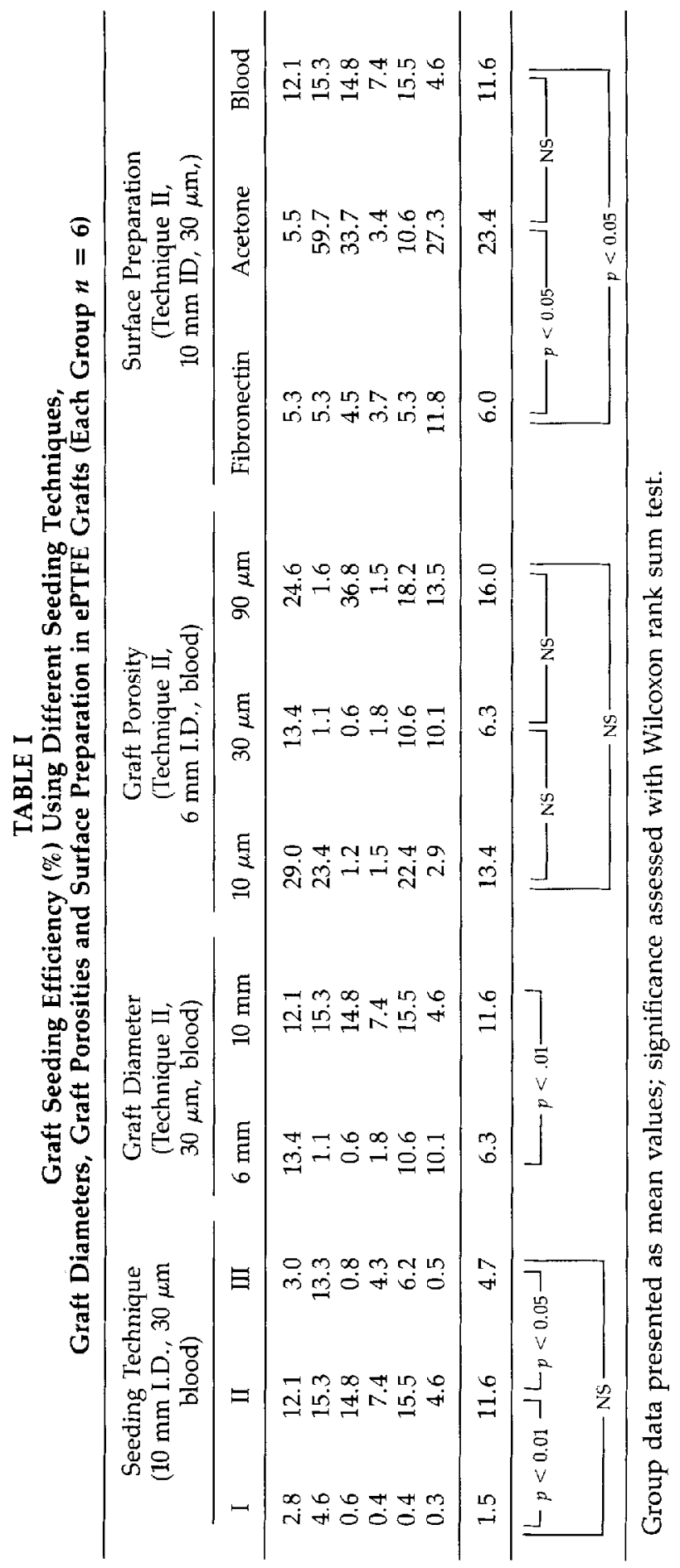




\section{Graft porosity}

The standard graft material, $(30 \mu \mathrm{m})$, had a seeding efficiency of $6.3 \%$ which was not significantly different from that of grafts with shorter $(10 \mu \mathrm{m})$ or longer $(90 \mu \mathrm{m})$ internodal distances, which were 13.4 and $16.0 \%$, respectively.

\section{Graft surface coatings}

The fibronectin-coated surfaces exhibited a $6.0 \%$ cell attachment, compared to $11.6 \%$ adherence in grafts coated with blood by seeding Method II, a difference that was significant $(p<0.05)$. The acetone-prepared surfaces had a $23.4 \%$ adherence, which was significantly $(p<0.02)$ greater than the $1.5 \%$ attachment with the milking technique of Method I, but was not statistically different from the $11.6 \%$ cell adherence with blood coating by Method II.

\section{DISCUSSION}

Autologous endothelial seeding of both Dacron and ePTFE prostheses in a canine model produces a confluent endothelial surface within a 4-week period. Improved patency of small caliber grafts prepared in such a manner has been documented in animal experiments. ${ }^{5}$ Endothelial cell harvesting and seeding must be optimal if this methodology is to have clinical usefulness.

${ }^{111}$ In-oxine labeling of endothelial cells provides a method for evaluating seeding efficiency. ${ }^{2}$ This technique, with measurement of gross radioactivity from attached endothelium, is a more accurate method of assessing total seeding efficiency than by radioautography or electron microscopy of random graft segments. Labeling, such as used in this study, does not appear to interfere with cell viability or adhesion in culture. There was very little leakage of the isotope from the tagged endothelium. Sharefkin and coworkers ${ }^{6}$ have reported a $71 \pm 10 \%$ attachment rate of freshly harvested cultured endothelial cells to Dacron grafts, compared to only $12 \pm 7 \%$ attachment to ePTFE grafts. This is not all that dissimilar from the $47 \pm 2 \%$ seeding efficiency of Dacron prostheses reported previously from our laboratory. ${ }^{7}$ The seeding efficiency of ePTFE reported in our current study is also comparable to those results of Sharefkin and coworkers. ${ }^{6}$ However, there is a clear difference in cell attachment using the milking procedure used in Sharefkin's study compared to our slightly different milking technique using a shorter incubation time. Greater cell attachment in the former study may reflect longer incubation times.

The manual milking procedure (I) and the mechanical spinning technique (III) in the current study resulted in lower rates of seeding than the two-step incubation method (II) in which cells were seeded onto a blood-coated sur- 
face. Differences in these procedures may be related to the graft's protein coating. However, longer incubation times could also account for improved cell adherence. Using the two-step incubation method, the comparison between 6 -and $10-\mathrm{mm}-\mathrm{I}$. D. grafts revealed a slightly higher seeding efficiency for the $10-\mathrm{mm}$ graft. This may simply reflect the larger surface area available for cell attachment in the larger-sized graft.

Among the three ePTFE porosities evaluated, the 90- $\mu \mathrm{m}$ graft type was thin-walled and was somewhat permeable, allowing easier wetting of the graft wall during the seeding process. However, there were no statistically significant differences in cell attachment. Thus, alterations in internodal distance or surface porosity, within the range tested, did not appear to affect the cell adhesion.

Rosenman et al. ${ }^{8}$ reported a seeding efficiency of $19.8 \pm 2.6 \%$ in 10-cm-long, 4-mm-I. D. porous and permeable ePTFE grafts having no external wrap. Unlike most previously published studies, these investigators did not rinse their grafts with heparinized blood, but instead, evaluated early cell loss soon after graft implantation. During the first $30 \mathrm{~min}$ of blood flow through the graft, $30 \%$ of the initially attached cells were lost. However, in the more porous and permeable graft used in their study, a large number of cells are probably trapped deep within the wall and are therefore less susceptible to detachment from flowing blood.

Seeger ${ }^{9}$ reported a seeding efficiency of $3 \pm 2 \%$ in 5-cm-long, 4-mm-I. D. ePTFE grafts seeded with freshly harvested endothelial cells, compared to an $8 \pm 5 \%$ efficiency when using primary cultured cells or a $7 \pm 14 \%$ efficiency with secondary cultured cells. These results are similar to our findings, but since the seeding techniques used differ, strict comparisons are not possible. One explanation for the slight variation in cell attachment found by Seeger ${ }^{9}$ could be that freshly harvested cells may still be subject to the influence of enzymes on surface receptors that lessens their ability to adhere to grafts.

In Seeger's study a considerable increase in seeding efficiency using a fibronectin-coated surface was reported. ${ }^{9}$ In our experiments we are unable to find an increase in seeding efficiency using a fibronectin versus a blood coated surface. Differences in both the fibronectin coating and seeding techniques could explain this discrepancy. An additional factor regarding these differences relates to trypsin's effect on surface membranes that might interfere with cell adhesion to fibronectin. ${ }^{10}$ Nevertheless, the procedures used in our study are among the most standard in practice by investigators studying endothelial seeding of prosthetic grafts. Low seeding efficiences in our study support the hypothesis that endogenous fibronectin may be important for cell adhesion, but that exogenous fibronectin does not improve cell attachment to ePTFE. ${ }^{11}$ In contrast, Dacron prostheses coated with collagen, fibronectin or plasma have been shown to have greater cell attachment compared to uncoated grafts. ${ }^{12}$ In addition, fibronectin surfaces in tissue culture flasks also exhibit greater cell attachment of trypsinized cells. ${ }^{2}$

The relative low seeding efficiency of ePTFE may in part be due to its hydrophobic surface. Acetone soaking of the surface reduces the graft's 
hydrophobicity and increases its wetability. The evaluation of such a surface revealed a $23.4 \%$ seeding efficiency, a value considerably higher than the $1.5 \%$ efficiency obtained when applying similar techniques to grafts not prepared in acetone.

Further studies of surface preparations are necessary to define an optimal seeding environment. A high seeding efficiency in certain situations may increase early graft thrombogenicity. Since many settings where autologous endothelial seeding of ePTFE grafts may be useful involve low-flow states, increasing initial thrombogenicity may reduce early patency, even if the later development of an endothelial surface might improve long-term patency. Lastly, preliminary studies as currently reported should allow investigators to standardize future experiments on endothelial cell seeding of prosthetic grafts.

Grafts were kindly provided by W. L. Gore, Inc, Flagstaff, Arizona.

\section{References}

1. J.W. Ford, W. E. Burkel, and R.H. Kahn, "Isolation of adult canine venous endothelium for tissue culture," in vitro, 17, 44-50 (1981).

2. J. B. Sharefkin, C. Lather, M. Smith, and N. M. Rich, "Endothelial cell labeling with indium-111-oxine as a marker of cell attachment to bioprosthetic surfaces," I. Biomed. Mat. Res., 17, 345-457 (1983).

3. G. Ramalanjaona, R. F. Kempczinski, J.E. Rosenman, and E. B. Silberstein, "The effect of fibronectin coating on endothelial cell kinetics in polytetrafluoroethylene grafts," J. Vasc. Surg., 3, 264-272 (1986).

4. J. M. Seeger, "Improved endothelial cell seeding density after flow exposure in fibronectin-coated grafts," Surg. Forum. 36, 450-452 (1985).

5. J. C. Stanley, W. E. Burkel, L. M. Graham, and B. Lindblad, "Endothelial cell seeding of synthetic vascular prostheses," Acta Chir. Scand. Suppl., 529, 17-28 (1985).

6. J.B. Sharefkin, C. Latker, G. Wind, D. Cruess, and N. M. Rich, "The comparative endothelial seeding efficiency of Dacron velour and expanded polytetrafluoroethylene vascular prostheses," Abstract at the 16 th Annual Meeting of the Association for Academic Surgery, San Diego, California, November 8, 1982.

7. L.M. Graham, J. W. Ford, D. W. Vinter, W. E. Burkel, and J. C. Stanley, "Improved endothelial cell adherence to Dacron vascular prostheses: optimizing of seeding technique (Abstract) 30th Annual Meeting of the American Society for Artificial Internal Organs, Washington, D.C., May 2, 1984.

8. J. E. Rosenman, W. H. Pearce, B. Silberstein, and R. F. Kempczinski, "Kinetics of endothelial cell seeding," I. Vasc. Surg., 2, 778-784 (1985).

9. J. M. Seeger and N. Klingman, "Improved endothelial cell seeding efficiency with cultured cells and fibronectin coated grafts," J. Surg. Res., 38, 641-647 (1985).

10. F. Grinnell, "Fibroblast receptor for cell substratum adhesion: Studies on the interaction of baby hamster kidney cells with latex beads coated by cold insoluble globulin (Plasma Fibronectin)," J. Cell Biol., 86, 104-112 (1980). 
11. D. M. Scott, J. C. Murray, and M. J. Barnes, "Investigation of the attachment of bovine corneal endothelial cells to collagens and other components of the subendothelium," Exp. Cell. Res., 122, 472-478 (1983).

12. S. K. Williams, B. E. Jarrell, L. Friend, J. S. Radomski, R. A. Carabasi, S. N. Mueller, S.C. Thornton, T. Marunicci, and E. Levine, "Adult human endothelial cell compatibility with prosthetic graft material," $J$. Surg. Res., 38, 618-629 (1985).

Received January 15, 1987

Accepted March 26, 1987 